\title{
Antonio Gómez López-Quiñones \\ Tentaciones post-revolucionarias: nostalgia y trascendencia en La flaqueza del bolchevique
}

\section{De los males del presente}

El primer largometraje de Manuel Martín Cuenca, La flaqueza del bolchevique (2003), aborda cuestiones, en principio, bastante dispares. $\mathrm{Su}$ trama fluctúa al menos entre tres líneas narrativas: el enconado enfrentamiento entre dos conductores, la ambigua relación entre una adolescente y un hombre maduro, y la monótona existencia de un economista. Todos estos hilos narrativos, tomados de la novela homónima del escritor Lorenzo Silva, ${ }^{1}$ aparecen trenzados en un argumento básico que podríamos resumir del siguiente modo. En una céntrica calle de Madrid, Pablo López (interpretado por Luis Tosar) colisiona accidentalmente con el automóvil de Sonsoles (Mar Requeras), una mujer de clase media-alta que demuestra poca paciencia ante el incidente. Ambos discuten y se insultan. Una vez zanjado el protocolo de daños y perjuicios, Pablo inicia una divertida pero también malévola campaña de llamadas anónimas contra Sonsoles. Siguiendo precisamente a esta última, Pablo conoce a una quinceañera, María, la única hija de Sonsoles. El personaje de María, que le valió a la joven actriz María Valverde el Goya a la Mejor Actriz Revelación y la Concha de Plata en el Festival de San Sebastián, sacude los pilares de la vida sentimental de Pablo. En sus conversaciones y salidas conjuntas, este personaje descubre en María una alternativa a su monótona cotidianeidad, pero ésta resulta abruptamente malograda. Sonsoles, al descubrir que Pablo es el responsable de las ofensivas llamadas, contrata los servicios de tres delincuentes para que lo intimiden con una paliza.

1 La novela de Lorenzo Silva fue publicada en 1997 por la editorial Destino y presenta una trama muy parecida a la de su adaptación cinematográfica. El cambio más importante corresponde seguramente al tono dramático del film, que contrasta con la atmósfera mucho más liviana del texto original. 
Éstos sorprenden a Pablo en compañía de María y, sin saber su identidad, matan a esta última tras intentar violarla.

La flaqueza del bolchevique, que en términos generales contó con una elogiosa recepción, también suscitó críticas que subrayaban su final taxativamente pesimista. En esta línea, Otti Rodríguez Marchante destaca que "la película es una tragedia cotidiana, una caída en las brasas o, mejor, rescoldos, de la juventud" (Rodríguez Marchante 2003). De manera análoga, Elsa Fernández-Santos observa en esta obra la desesperanza de "una tragedia clásica" (Fernández-Santos 2003). Finalmente, Julio Rodríguez Chico hace hincapié en el "fatalismo" de su cierre (Rodríguez Chico 2003). Es obvio que estas recepciones intentan evaluar el (des)acierto estético de algunos giros narrativos. Por otro lado, en esta estructura formal anida una interesante reflexión sobre el momento histórico que aborda el film. En el fondo, esta historia de ejecutivos desencantados y cautivadoras "lolitas" deja ver las contradicciones de un momento post-revolucionario en el que los deseos imposibles de trascendencia se traducen en la articulación nostálgica de una redención sentimental finalmente inviable.

Es importante, antes de seguir con este análisis, explicar al menos dos de estos conceptos, "momento post-revolucionario" y "trascendencia". Con el primero me refiero al momento histórico que, en Europa, se abre después de la caída del muro de Berlín y el desmoronamiento del bloque soviético, y que da paso a un periodo de expansión e intensificación capitalistas. Ésta fase ha recibido su formulación más celebre en el (duramente contestado) volumen de Francis Fukuyama, The End of History and the Last Man (1992). De los argumentos de Fukuyama me interesa su concepción del parlamentarismo liberal y las sociedades de mercado como el modelo diacrónicamente culminante y geográficamente destinado a la universalidad. Incluso los autores más críticos con esta visión escatológica de la historia, reconocen que 1) la conjunción de capitalismo y democracias formales se ha convertido, como afirma David Harvey, en un severo límite conceptual y práctico (Harvey 2000: 258); y que, en este contexto, 2) el imaginario revolucionario moderno inaugurado por la Revolución Fran- 
cesa y continuado por la Revolución Rusa ha entrado, como explica John Foran, en una fase de impasse (Foran 1997: 1). ${ }^{2}$

Con el término "trascendencia" no aludo, por otra parte, a los dos significados más comunes del término. Mi uso no apunta a ningún ámbito de orden supra-terrenal. Tampoco tengo en mente una trascendencia terrenal que, al modo del idealismo kantiano, ubica aspectos de la existencia humana en un esfera trans-temporal de a prioris (categorías como espacio o tiempo) que hacen posible precisamente el conocimiento de lo temporal. En este ensayo, la trascendencia tan solo implica la posibilidad de superar unas determinadas circunstancias históricas. Alex Callinicos formula este tipo de trascendencia del siguiente modo:

Transcendence in the sense in which I am interested in it embraces in particular innovation in the social, political and intellectual realm. How are we able to go beyond the limit set by existing practices and beliefs and produce something new? (Callinicos 2006: 1).

Desde esta perspectiva, la búsqueda de una trascendencia conlleva cambios de carácter secular y la negación de un status quo, pero no de la historia misma. Esta última es la dimensión en la que las acciones individuales y colectivas tienen la oportunidad de producir una reorganización social, un nuevo entendimiento político e incluso nuevas coordenadas de subjetividad e inter-subjetividad. Ésta es una trascendencia inmanente y material cuyas condiciones de posibilidad se encuentran en el presente, en la radical transformación de aspectos esenciales de éste. En conclusión, esta trascendencia es un futuro que tiene que confrontar lo inmediato en sus propios términos sin atajos espiritualistas ni teológicos.

Es en este contexto en el que la gran disyuntiva del personaje protagonista del film, Pablo, adquiere su sentido. Este personaje habita un tiempo post-revolucionario en que la misma idea de una trascendencia social ha perdido incluso su legitimidad teórica, pero en el que aún queda el recuerdo de esa posibilidad o del momento histórico y biográfico en que dicha posibilidad resultaba factible. Todo este debate aparece en La flaqueza del bolchevique, pero lo hace como telón de

2 El propio Foran comenta que esta tradición es continuada en los años treinta y sesenta del siglo veinte. Es en los años setenta cuando, en un nuevo marco geopolítico internacional, dicha tradición es deslegitimada como fantasía seudoutópica y nociva. 
fondo de los encuentros entre Pablo y María. Mi impresión es que, sin el análisis detallado de este decorado de situaciones secundarias, la naturaleza última de dicha relación no puede ser entendida correctamente. De este contexto voy a destacar tres elementos: la empresa para la que trabaja Pablo, el estrato social al que éste pertenece y el tipo de relaciones que mantienen todos los personajes. La empresa de Pablo es una agencia bancaria encargada de la arquitectura de una compleja transacción financiera. Las actividades económicas de esta entidad se enmarcan, por lo tanto, en un modelo de producción postfordista y post-taylorista en, al menos, dos sentidos. En primer lugar, ni Pablo ni ninguno de sus compañeros producen ningún objeto tangible. Toda su labor se desarrolla en un ámbito virtual de operaciones informáticas con fondos financieros abstractos y altamente móviles. Éste es un tipo de trabajo especulativo y auto-referencial: dinero que en su relación consigo mismo produce más dinero (Waters 2001: 8588). En segundo lugar, la estructura de la propia empresa no responde al modelo hiper-jerárquico y compartimentalizado de la mega-organización industrial. Pablo no sabe realmente para quien trabaja porque sus labores diarias se integran en una red de subcontratas y colaboraciones temporales. Su núcleo laboral inmediato incluye un reducido grupo de personas en el que hay un jefe, pero en el que, como demuestra el despido de una colega (Alba, interpretada por Yolanda Serrano), el control se produce de una manera más horizontal y también más intensa. ${ }^{3}$ Este nuevo esquema de organización, que prioriza comunidades laborales más reducidas y auto-responsables de sus propios resultados, responde (como han explicado Luc Boltanski y Eve Chapiello en un ensayo seminal sobre el tema) a un capitalismo en el que priman la concentración trasnacional de capitales y una descentralización de su propio modus organizandi (Boltanski/Chapiello 2005: 255275).

Si éste es el escenario de buena parte del film, ¿quién es Pablo? ¿a qué nueva clase social pertenece? ¿por qué nueva estructura laboral

3 Alba es un personaje de origen latinoamericano que trabaja como asistente personal de Pablo. Alba intenta aprender la dinámica de su trabajo con cierta dificultad y Pablo procura protegerla, callando ante sus errores. Otro de sus colegas detecta estos problemas y los reporta. Este incidente ofrece la impresión de que el control no se realiza en esta empresa de manera totalmente vertical sino más bien horizontal ya que todos los empleados se vigilan mutuamente. 
aparece definido este personaje? Él mismo, en una conversación con una compañera, afirma que en sus desplazamientos de trabajo siempre encuentra el mismo tipo de gente:

Viajan en business, se alojan en hoteles caros, son jóvenes, ganan buenos sueldos, y de vez en cuando se pueden pillar algún puente de vacaciones. Lo malo es que el resto del tiempo están siempre disponibles, como las putas, porque su función consiste en hacer cualquier cosa que les pidan y fingir que les da gusto, y así mientras pringan y sonríen se les va la vida, casi sin darse cuenta. Tu y yo, por ejemplo.

El angst que traslucen estas palabras será abordado más adelante. En este punto, me importa hacer hincapié en que Pablo ha detectado el surgimiento de una clase que, independientemente de su adscripción nacional, comparte un estilo de vida, narrativas existenciales, preferencias estéticas y una post-ética profesional que los hace inmunes a lealtades geográficas o culturales. Esta paradigmática figura de algunas sociedades contemporáneas conforma "a new managerial class" o "the transnational citizenship" que, como explica Aihwa Ong, "do not, practically speaking, rely on a specific citizenship status to make a living but travel the world to perform globalized functions in the nodes of a far-flung archipelago" (Ong 2006: 239). Esta misma autora enfatiza que el circuito laboral en el que se mueve esta clase directiva es altamente inestable e inseguro, y su gran valor es el riesgo. Es por esto que la propia Ong añade que esta clase "is rooted in an instrumentalist definition of individual freedom as economic optimization in the realm of borderless markets" (Ong 2006: 238).

Esta concepción del sujeto, implícita en los argumentos de Aihwa Ong, podría servir como marco para conceptualizar las reglas que rigen las relaciones de todos los personajes en La flaqueza del bolchevique. Este film esboza una colectividad urbana de sujetos autónomos cuya interacción con otros sujetos resulta siempre problemática. Los "otros" emergen como engranajes de una dinámica hiper-competitiva o como límites a la libertad individual. No es exagerado afirmar que, al menos, el cincuenta por ciento de las escenas del film están construidas sobre dos fórmulas elementales de interacción. En primer lugar, llamadas telefónicas en las que, por algún motivo, uno de los hablantes tiene que modificar o esconder su verdadera identidad. En segundo lugar, persecuciones en las que un personaje sigue a otro por la urbe, obteniendo una información que habría sido imposible obtener 
de otra manera. Las relaciones asentadas en un contacto personal y no mediado tienen por su parte una orientación instrumental o un destino nefasto. Entre las primeras destacan, por ejemplo, las que protagonizan Pablo y sus colegas del banco, o Sonsoles y el policía que contrata a los tres delincuentes. Entre las segundas sobresale la que mantienen Pablo y María (que, como ya sabemos, termina trágicamente). ${ }^{4}$ En resumen, los tres aspectos aquí destacados (la esfera empresarial por la que Pablo aparece radicalmente condicionado, el estrato social de los nuevos gestores del capitalismo transnacional y la dinámica instrumental que administra el contacto de unos personajes con otros) revelan el horizonte histórico que este film reconstruye para su propia trama. Otros sub-temas implícitos en La flaqueza del bolchevique, como la soledad, la incomunicación, el desgaste de la intimidad, la despersonalización o la rutinización de lo cotidiano, deben ser entendidos como piezas de un puzzle mayor con tema propio: los retos de una cultura, como la española, sometida en las dos últimas décadas del siglo XX a un acelerado proceso de rápida reorganización modernizadora.

4 En este Madrid de sujetos atomizados donde el "otro" es una fuente de ansiedad o destrucción no parece demasiado difícil detectar el ethos neoliberal "[that] has conceived human societies as collections of autonomous individuals pursuing their own personal goals only subjected to a neutral framework of laws that prevents these individuals from interfering with each other's actions" (Jardine 1998: 33). Dos aspectos de esta cita deben ser destacados en relación al largometraje de Martín Cuenca: 1) el estatus de otros personajes respecto a cualquier individualidad es esencialmente negativo, su lugar es o debe ser la no-interferencia y la noingerencia; 2) el contacto con esos otros personajes resulta, por lo tanto, tolerable siempre que favorezca (y no entorpezca) el desarrollo de los proyectos y deseos propios. Esta es la versión de liberta negativa que John Stuart Mill célebremente privilegia en On Liberty (1859). En otras palabras, este Madrid parece una plasmación cinematográfica del temor que tantos filósofos de la modernidad europea (como Max Weber o Theodor Adorno) dejaron plasmado en el concepto de razón-instrumental. Ésta convierte la comunidad en un circuito especulativo donde la utilidad y rentabilidad de todo lo real priman sobre la discusión de los fines últimos. Es por esto que Weber afirma que, bajo la impronta de esta lógica, "expectations are used as 'conditions' or 'means' for the attainment of the actor's own rationally pursued and calculated end" (Weber 1978: 26), y es por esto que Adorno concluye que el dominio y el control constituyen el último objetivo de dicha razón (Horkheimer/Adorno 2002: 3-42). 


\section{Nostalgias vacías: El pueblo y la revolución}

El análisis hasta ahora presentado no solo atañe, en realidad, a este film aislado, sino a toda una familia de recientes largometrajes españoles preocupados por una temática parecida. En obras como Adosados (Mario Camus 1996), Pesadilla para un rico (Fernando Fernán Gómez 1996), Familia (Fernando León de Aranoa 1996), Extraños (Imanol Uribe 1990), Smoking Room (Roger Gual y Julio Wallovits 2002), Las horas del día (Jaime Rosales 2003), El método (Marcelo Piñeyro 2005) o Concursante (Rodrigo Corés 2007), encontramos personajes aquejados de una maladie similar, una suerte de afección de época: el hombre urbano de la democracia española, bien situado profesional y económicamente, descubre en su existencia un patrón de repeticiones que desencadenan la añoranza por mayores márgenes de libertad, espontaneidad para la acción y opciones de un cambio profundo. Frente a la osificación de una vida cómoda pero predetermina$\mathrm{da}$, surge la necesidad (fracasada en todos estos filmes) de una verdadera ruptura, de la emergencia de la excepción, de una superación de lo que se presenta como los límites de lo posible. En donde La flaqueza del bolchevique difiere de estos filmes es en el pasado de su protagonista, ya que Pablo debe afrontar dos dificultades complementarias: las claustrofóbicas demarcaciones de un contexto histórico, pero también el recuerdo de un tiempo biográfico e histórico en el que dichas demarcaciones pudieron ser cuestionadas. En definitiva, Pablo es consciente de habitar un ciclo post-revolucionario, pero aún atesora la memoria de otra época menos categórica.

Esta memoria tiene, como ya se ha mencionado, una doble fuente: una biográfica y otra historiográfica. Ambas aparecen en el film entrelazadas. En primer lugar, Pablo admite ante María que su vida sufrió un giro rotundo al terminar su licenciatura universitaria. En esas mismas fechas, Pablo comienza una tesis doctoral que abandona casi de inmediato. "Aparecieron en la facultad unos señores muy elegantes", explica este personaje, "y dijeron: "A ver, ¿quiénes son los chicos más inteligentes de esta facultad?'. Y yo era uno de aquellos chicos, con mi hermoso expediente y dispuesto a comerme el mundo. Y sí, aprendí a ganar mucho dinero, pero no sé quién se ha comido a quién”. En esta charla, Pablo expresa no solo el desagrado ante su trayectoria vital, sino también la nostalgia por espacios de su infancia y juventud. 
Aunque llega a mencionar explícitamente algunos de estos espacios (como el piso donde vivía como estudiante o el pueblerino barrio de su niñez), éstos no tienen tanta importancia por su contenido, como por su capacidad de sostener el espejismo de un origen y también (y sobre todo) de un sentido dotado de plenitud, un signo capaz de trasmitir estabilidad. Kathleen Stewart argumenta que este tipo de narrativas tienen un punto de origen bastante concreto: "in the disorganizing and all pervasive economy of late capitalism, awash in a sea of faces, we look back nostalgically to the shore in a sudden memory of a ground already lost" (Stewart 1988: 228-229). En los tres elementos barajados por esta cita se sostiene el breve retrato autobiográfico de Pablo: la confusión de alguien inmerso en la vanguardia de la economía capitalista, la tonalidad nostálgica de una mirada retroactiva y el recuerdo casi epifánico de una "tierra" que, sin importar demasiado su referente histórico, devuelve una base de certidumbres (o, al menos, su ilusión).

En la postura de Pablo hay otro ingrediente memorialístico no estrictamente biográfico. Pablo no solo menciona el abandono de la tesis doctoral, sino también su tema: la Revolución Rusa. Este detalle no tendría mayor importancia si no fuera porque reaparece en otros momentos de los que vamos a destacar tan solo dos: 1) las primeras imágenes del film muestran a Pablo pasando las páginas de una historia ilustrada de la Revolución Rusa; 2) en un momento posterior, Pablo se define políticamente ante María (no sin cierta ironía) como bolchevique. El propio título del film se deriva de este juego de menciones explícitas al alzamiento de 1917. Constituiría un error llevar demasiado lejos la interpretación de esta sub-trama, proponiendo, por ejemplo, para Pablo la identidad herida de un comunista desencantado que extravió sus ideales políticos en el sendero de la Historia. Mi interpretación va en otro sentido: la Revolución Rusa funciona en La flaqueza del bolchevique como un tropo de una edad biográfica más abierta y de un momento histórico muy evocador.

Ahora bien, la pregunta más importante es por qué éste y no otro suceso. En primer lugar, si Pablo padece el síndrome de la trascendencia imposible, no debe sorprender que (aunque sea a un nivel emotivo $\mathrm{y}$, en menor medida, político) le cautive uno de esos momentos casi épicos en el que la posibilidad de una trascendencia social se materializó en forma de crisis y revolución. Incluso en un reciente y crítico 
recuento de aquella insurrección, se admite que hay algo en ésta especialmente evocador en mitad de un periodo "that conspires [...] to discourage the belief that it [the world] cannot be radically reordered" (Smith 2003: 168). No hay que coincidir con los propósitos y efectos de la Revolución Rusa para reconocer su poder evocativo en el imaginario popular del siglo XX. En segundo lugar, y en relación con este último punto, los eventos iniciados en 1917 dejaron una rica iconografía, un inmenso abanico de signos que han permito a Orlando Figes y Boris Kolonitskii hablar de una compleja revolución semiótica, "the symbolic battlefield of the revolution" (Figes/Kolonitskii 1999: XX). Pablo se sirve de elementos de esta iconografía para materializar el objeto de su nostalgia. La palabra "bolchevique" o algunas imágenes fotográficas de Trotsky y Lenin adquieren para este personaje una consistencia semántica especial, no identificable (no plenamente, al menos) con la añoranza por un proceso político concreto. La aparición esporádica de la Revolución Rusa funciona como un síntoma de los males que afligen al protagonista. Si, como afirmaba anteriormente Kathleen Stewart, la nostalgia necesita de objetos catalizadores, Pablo encuentra estos soportes materiales en 1) su infancia-juventud y 2) en un acontecer histórico suficientemente poderoso, lejano y maleable como para sustentar sus anhelos de una realidad distinta a la suya.

Resulta evidente que esta interpretación del film resta importancia política a la presencia de la Revolución Rusa. Adopto este acercamiento porque el propio largometraje tematiza dicha revolución como un evento ideológicamente hueco para la contemporaneidad histórica de los personajes. Esta revolución pesa (y mucho) en la trama, pero pesa porque los dos protagonistas, Pablo y María, la asumen como con un decorado sin profundidad. La insurrección de 1917 es uno de sus primeros temas de conversación, pero la complicidad que facilita este diálogo convierte unos acontecimientos pretéritos, según los términos de Fredric Jameson, en una superficie especular con poca o nula sustancia histórica (Jameson 1999: 279-296). Debemos notar que si bien Jameson se refiere a un tipo de representación nostálgica y kitsch del pasado en el cine norteamericano de los años noventa, utilizo su observación de manera un tanto distinta porque La flaqueza del bolchevique no es una pieza histórica, sino un film sobre el uso estético que el presente hace de un pasado percibido como incomprensible o irrelevante. De manera sintética, se podía resumir este uso señalando el 
acercamiento hiperbólico de Pablo y la aproximación mnemotécnica de María.

El primero presenta sus credenciales políticas como las de un bolchevique. Ante el desconcierto de la adolescente, Pablo aclara que los bolcheviques, a diferencia de los socialistas, "no nos conformamos con quitarles todo a los ricos porque eso no cambiaría nada. Lo que hay que hacer es fusilarlos a todos, a los ricos primero y a los pobres después". Aunque estas palabras son emitidas con una clara intención humorística, Pablo disuelve por exageración la realidad específica de un grupo político que él investigó para su tesis. Su glosa no pasa por la definición más o menos esquemática, sino por una rápida caricatura que exagera y, por lo tanto, cancela la realidad del proyecto político que el bolchevismo representó. Inmediatamente después de esta boutade, Pablo añade: "No soy bolchevique, no soy nada y, si fuese algo, dejaría de serlo por ti”. La operación intelectual de Pablo revela el pathos de un personaje hastiado que no encuentra anclaje ni en la Revolución Rusa pero tampoco (y esto es lo decisivo) en una crítica coherente de ésta. Su gesto crítico es doble. Pablo rechaza un presente claustrofóbico, pero reconoce que, en esta coyuntura, cualquier aspiración radicalmente contestataria carece de verdadera viabilidad.

Por su parte, María intuye que Pablo está bromeando y sonríe sin darle importancia al comentario. En un momento muy posterior, será ella quien retome el asunto: “¿Bolchevique? Miembro de la fracción dura que formaba el ala izquierda del Partido Obrero Socialdemócrata de Rusia. Ayer lo miré en una enciclopedia. Creía que te lo habías inventado". Si la intervención de Pablo está marcada por el exceso, la de María se caracteriza por abordar la Revolución Rusa como una entrada más en una obra recopilatoria. De alguna manera, la reacción de María confirma la postura de Pablo, ya que el acercamiento de ésta al suceso que marcó el desarrollo de la izquierda e historia europeas aparece lastrado por dos aspectos. En primer lugar, ella repite la definición que ha memorizado sin entender realmente su sentido. En su recitación, María emplea una prosodia mecánica, demasiado perfecta. Es claro que este personaje ha querido retener palabra por palabra para impresionar favorablemente a Pablo, pero también porque estos vocablos explican una realidad ininteligible para ella. Más que un conocimiento histórico, María adquiere y trasmite un cuadro vacío y espectral, una fachada de términos rimbombantes que, en expresión de Eli 
Friedlander, "is produced for easy consumption [creating] a form of false consciousness [...], satisfying artificial needs by means of substitutes of culture" (Friedlander 1997: 379). En la adquisición cognoscitiva de María son fácilmente apreciables el "consumo fácil", la "falsa conciencia histórica" y la "substitución de la cultura" por una cascada de vocablos sin profundidad semántica.

En segundo lugar, la relación de María con un pasado tan relevante para el imaginario personal de Pablo está distorsionada por un modelo enciclopédico de conocimiento. La enciclopedia almacena datos en un afán sintético y totalizante que sistematiza el mundo de acuerdo, no a un esquema narrativamente moral, sino alfabético. En la enciclopedia hay un impulso objetivizador que, al abordar el pasado y a los que lo protagonizaron, "it destroys others as lives and re-incarnates them as things, as historical event" (Eaglestone 1998: 317). En el breve exordio de María sobre los bolcheviques se percibe el proceso reificador de una enciclopedia sobre su objeto de conocimiento. En el supermercado de pasados historificados, María toma lo que necesita para ponerlo en circulación sin demasiado interés en esas implicaciones ideológicas que, como explica Matthias Fritsch, "permit[s] the ethical and political subject to be responsive to others in the first place" (Fritsch 2001: 289). De cualquier forma, el acercamiento de María a la Revolución Rusa no importa realmente por la información que brinda sobre este personaje. En este punto específico, María se comporta como una metonimia de un ambiente político mucho más amplio. Una vez que consideramos las palabras de ambos personajes conjuntamente, podemos reconsiderar La flaqueza del bolchevique como un comentario sobre el destino neoliberal de una España en la que las grandes aspiraciones revolucionarias del siglo XX han quedado reducidas a definiciones de diccionario que Pablo deforma y María repite sin saber su significado.

\section{Lolitismo y capitalismo}

En el contexto anteriormente planteado, la relación sentimental de los dos personajes puede ser comentada adecuadamente. La fascinación de Pablo por María se adecua, en términos generales, a la narrativa del "lolitismo", en la que la ingenua y perversa sexualidad de una adolescente desestabiliza un determinado orden social. Como asevera Sarah 
Hentges, esta sexualidad supone un motivo de incomodidad y deseo que trasluce las profundas contradicciones de una comunidad (Hentges 2006: 7-19). Lo importante de estas reflexiones es que si la figura cinemática de la niña-mujer ha dado pie, como explica Ilana Nash, a la hiper-sexualización de personajes femeninos y a su tratamiento dicotómico "madonna/whore" (Nash 2006: 3), también ha funcionado como "an exasperating agent of chaos who challenged the boundaries and hierarchies of a patriarchally organized society" (Nash 2006: 2). Para situar correctamente La flaqueza del bolchevique debemos retener el eje central de las ideas expuestas por Nash y Hentges: la sexualidad actúa en estas narrativas como un escenario de crisis para instituciones políticas y sociales muy diversas. En el film de Martín Cuenca, esta conexión aparece claramente trazada en la primera escena. En ésta descubrimos a un taciturno Pablo pasando las páginas de un grueso volumen sobre la Revolución Rusa. Los primeros planos de este personaje son entrecruzados con planos de las propias imágenes del libro (una fotografía del joven Trotsky o la estampa de Lenin en un avanzado estado de senectud). En un momento dado, Pablo recupera la concentración ante un retrato que capta todo su interés. Esta fotografía no retrata a grandes figuras políticas, sino a las cuatro hijas del Zar Nicolas II (Olga, Tatiana, María y Anastasia Romanota) cuando aún eran niñas, varios años antes de su fusilamiento el 17 de julio de 1918.

Éste es uno de los momentos más informativos de La flaqueza del bolchevique. Esta escena podría ser interpretada, de hecho, como un resumen de los temas desarrollados con posterioridad. Pablo observa distraído la historia ilustrada de la Revolución Rusa porque ésta ha adquirido el estatus espectral de una ruina biográfica e histórica. Ahora bien, en mitad de dicha ruina, la estampa de cuatro niñas/adolescentes (claro anticipo del personaje de María) reactiva poderosamente su atención. Es ahora cuando podemos volver sobre las preguntas que dejamos suspendidas al inicio del ensayo: ¿Qué significa para Luis la adolescencia femenina? ¿qué rol cumple su trato con María? ¿por qué el cierre tan categórico del film implica un final coherente para toda la narración? La respuesta a estas preguntas pasa por tres argumentos distintos. En primer lugar, para este personaje, el contacto con la adolescente conlleva el aura de la trasgresión porque, en el marco de una esfera profesional presidida por el ennui fastidioso de una nueva buro- 
cracia mercantil, Pablo observa a María como un auténtico acontecimiento imprevisto que rompe el horizonte de sus expectativas previas.

En segundo lugar, María no es una adolescente cualquiera, sino un personaje inteligente y directo que a Pablo le devuelve el espejismo de su propia refundación. María viene de una procedencia privilegiada, pero enjuicia con cierta agudeza sus propias circunstancias. Pablo empatiza con este personaje por su talante crítico, pero también porque, como comentan Frances Gateward y Murria Pomerance, la adolescencia en el cine occidental posterior a la Guerra Fría ha implicado una esperanza específica con la que personajes como Pablo ya no cuentan: "Developing a sense of independence and finding a place of one's own" (Gateward/Pomerance 2002: 17). La adolescencia acumula tanto valor simbólico-político porque es un proceso y alberga posibilidades aún realizables. No se entiende la cultura sentimental de Pablo si no es contra este fondo: el hombre maduro que tuvo aspiraciones izquierdistas más o menos concretas y que hoy observa su vida como una labor hecha y cerrada en el seno de un capitalismo severo. Este sujeto descubre (o fantasea) en una adolescente la idea misma de un porvenir impredecible.

En tercer lugar, María también suscita en Pablo reflexiones sobre un contexto semi-rural rememorado en clave nostálgica. En sus conversaciones, Pablo recuenta su trayectoria desde la clase trabajadora hacia la nueva burguesía rectora, desde las ilusiones ideológicas hacia un nihilismo sufriente, y también desde un alejado barrio/pueblo de la periferia madrileña hacia el centro financiero de la ciudad. ${ }^{5}$ Otra de las ilusiones que Pablo cree recuperar al conocer a María es la posibilidad de un retorno al barrio casi rural y periférico en donde creció. Todas sus conversaciones sobre este espacio pre-urbano están dotadas de una tonalidad emotiva que Maruška Svašek ha rastreado en narrativas

5 La oficina de Pablo ofrece una estupenda vista panorámica de la Puerta de Europa, más conocida como las Torres Kio, de 114 metros de altura cada una. Estos edificios fueron finalizados en 1996 y su diseño corrió a cargo de los arquitectos Philip Johnson y John Burgee. Lo realmente relevante de estas torres es que fueron el objeto de uno de los casos de corrupción económica más sonados de la democracia española. Estas torres constituyen, por lo tanto, iconos de un periodo de la historia española conocida como "la cultura del pelotazo", caracterizada por la especulación y el desorden financiero. No es de extrañar que Álex de la Iglesia, en un claro giro mordaz, atribuyera a estos edificios un poder intrínsecamente demoníaco en su film El día de la bestia (1995). 
post-socialistas centradas en contextos geográficos donde la dinámica del capitalismo se deja notar con menos intensidad (Svašek 2006: 12). Pablo rememora ante María el viejo barrio, ambos se encuentran con un compañero de aquellos años que se dedica al trabajo social y, finalmente, para su última cita, deciden desplazarse a este suburbio y, en concreto, a "un lugar muy especial" que Pablo recuerda con gran apego: una explanada desde la que se divisa una perspectiva panorámica de Madrid. Ambos encuentran este lugar y pueden, durante unos segundos, observar la ciudad desde fuera, como un espectáculo estético y, por primera vez, placentero. Durante estos instantes, resulta evidente que María ha posibilitado una vuelta a un locus simbólico que se corresponde con un origen que Pablo (así lo percibe él mismo) ha traicionado y dejado atrás. Esta adolescente facilita la impresión de cercanía, por lo tanto, a unas raíces biográficas, geográficas y culturales.

Una vez tenidos en cuenta los tres puntos anteriores, el trágico final de La flaqueza del bolchevique debe entenderse como un cierre coherente para las problemáticas planteadas por la narración. Dos razones me parecen relevantes para sostener esta afirmación. En primer lugar, se podría hablar de María como una figura discursivamente sobrecargada. Esta joven funciona como un punto de sutura en el que, por un instante, quedan resueltos los constreñimientos que hacen del día a día de Pablo una experiencia poco grata. En este sentido, María queda redimensionada por las necesidades que otro personaje proyecta sobre ella. Con su muerte, lo que realmente desaparece para Pablo es el globo retórico que ha construido alrededor de ella. En segundo lugar, hay otro factor que, no por evidente, deja de resultar decisivo en el proceder de Pablo. El fenómeno que estimula su interés tanto en María como en las cuatro hijas del Zar Nicolas II es su enorme belleza. Este hecho es determinante porque muestra el curioso trasvase de intereses que este personaje lleva a cabo al saltar de unos problemas a sus posibles soluciones.

Estos problemas gravitan en torno a unas condiciones vitales y éstas son a su vez el producto del desarrollo particular de un país como España y de una ciudad como Madrid, convertidos en enclaves de un circuito internacional de capitales financieros. Este entorno nada tiene que ver con la urbe festiva y transgresora, plasmada en tantos filmes, por ejemplo, de Pedro Almodóvar o Fernando Colomo. La producción 
especulativa, la competitividad y el control empresarial parecen haber sustituido al impulso celebratorio de otras décadas. ${ }^{6}$ Todas estas dificultades (que son inherentes a la evolución política, social y económica de un contexto) resultan en gran medida tergiversadas por Pablo quien, en un clásico giro formalista de rechazo a procesos modernizadores, "sought in aesthetic experience a refuge from a debase and mediocre social world" (Callinicos 2007: 181). María no solo ocasiona el asombro admirativo, sino también la decisión de que su cautivadora belleza sirva de redención para todo lo demás. Las circunstancias en que María fallece dejan en evidencia la debilidad de esta lógica: si Pablo inventa en este personaje la posibilidad de un nuevo comienzo para sí mismo y la vuelta al territorio prometedor de su propia juventud, el tajante final nos recuerda que todas esas aspiraciones exigen mucho más que la fascinación por una seductora joven. Es más, la fascinación trasgresora por una adolescente debe ser entendida, utilizando los términos de Martha Nussbaum, en el marco de una antropología eroticista que ofrece sustento a políticas anarquistas de carácter amoral (Nussbaum 1999: 43). Los mismos problemas de los que Pablo viene huyendo lo persiguen hasta la periferia para reiterar su lógica y para mostrar que la trascendencia no será el resultado de determinados valores estéticos ni de la erotización per se de la trasgresión moral.

En La flaqueza del bolchevique, el fatalismo no proviene por lo tanto de su desesperanzadora última escena, en la que Pablo ingresa en prisión e imagina la imagen de María sobre la pared de su celda. El fracaso de este personaje está prefigurado en los términos idealizadores y estetizantes con que confronta su angustia. Todos los ingredientes que confluyen en su relación con María pueden ser explicados como tentaciones post-revolucionarias. La exaltación de la juventud, la fetichización de la belleza y la nostalgia por un origen perdido surgen como salidas en falso para un entorno que exige otro tipo de reformas. Todas estas soluciones no solo ensayan una escapada de la Historia, sino también el tratamiento de ésta como un decorado discontinuo de donde extraer esencias absolutas y descontextualizadas (la

6 Randolph Pope explica que en algunas recientes novelas española "Madrid has become a playground" (Pope 2008: 135). Pope añade que "the city has lost its previously local character and is now just another global metropolis" (Pope 2008: 135). Por supuesto, el cine de Almodóvar, al menos él de los años noventa, podría ser citado como otro ejemplo de esta urbe lúdica. 
"juventud", la "belleza" o el "origen"). El verdadero determinismo de La flaqueza del bolchevique tiene, por lo tanto, otra causa: la ausencia de materiales disponibles con los que Pablo podría articular una respuesta más consistente. En esta coyuntura, el film, propone una crítica de lo que Terry Eagleton ha denominado "a 'bad' or premature utopianism" que, según este mismo autor, "grabs instantly for a future, projecting itself by an act of will or imagination beyond the compromised political structures of the present" (Eagleton 1990: 229). Pablo incurre en este "utopismo prematuro" (denominado en este ensayo "tentaciones post-revolucionarias") justamente porque, a su alrededor, no encuentra las herramientas con las que desencadenar algún tipo de ruptura y, por ende, de trascendencia social.

Una última cuestión se desprende de este planteamiento: ¿qué consecuencias se pueden extraer de unas circunstancias históricas que se imponen ante Pablo como un entramado opresivo y, sobre todo, infranqueable ( $\tan$ infranqueable que antiguas alternativas parecen reducidas a un simple decorado y las nuevas alternativas no han surgido aún)? En este aspecto, el film parece ofrecer la más negativa de las respuestas. Si no existe aún una auténtica contestación utópica y si las fugas post-revolucionarias conducen al protagonista al fracaso más estrepitoso, la única opción radica en un estado de reflexiva pasividad. Los dos últimos planos del film (Pablo con la mirada fija en la pared mientras imagina a María sobre el blanco de la celda) cifran el dilema de un sujeto aislado en la pura digresión imaginativa y contra-factual que sirve de último pero paralizante consuelo. En este planteamiento hay además algo circular ya que propone un problema sin solución: un conjunto de males coyunturales para cuya superación, tal y como afirma Slavoj Žižek, no se dan las circunstancias históricas ni se van a dar en un futuro previsible (Žižek 1999: 352). Lo relevante de este final es que compendia visualmente el cul-de-sac en el que se encuentra la imaginación política (marxista y no marxista) cuyo techo especulativo aún continúa siendo una sociedad capitalista. La circularidad de este instante es trágica porque, como Pablo descubre a lo largo del film, hay que pensar una sociedad post-capitalista cuando, sin el capitalismo (en cualquiera de sus variantes), resulta imposible concebir y estar en la realidad. 


\section{Bibliografía}

Boltanski, Luc/Chapiello, Eve (2005): The New Spirit of Capitalism. London: Verso.

Callinicos, Alex (2006): The Resources of Critique. Cambridge: Polity.

- (2007): Social Theory. A Historical Introduction. Cambridge: Polity.

Eaglestone, Robert (1998): “The 'Fine Risk' of History. Post-structuralism, the Past and the Work of Emmanuel Levinas”. En: Rethinking History, 2, 3, pp. 313-320.

Eagleton, Terry (1990): The Ideology of Aesthetic. Oxford: Blackwell Publishing.

Fernández-Santos, Elsa (2003): "Martín Cuenca debuta con la historia de amor de un ejecutivo y una niña". En: <www.elpais.com/articulo/cine/Martin/Cuenca/debuta/ historia/amor/frio/ejecutivo/nina/elpepuculcin/20031031elpepicin_5/Tes $>$ (13.08.2008).

Figes, Orlando/Kolonitskii, Boris (1999): Interpreting the Russian Revolution. The Language and Symbols of 1917. New Haven: Yale University Press.

Foran, John (1997): “Introduction”. En: Foran, John (ed.): Theorizing Revolutions. London: Routledge, pp. 1-10.

Friedlander, Eli (1997): "Some Thoughts on Kitsch". En: History and Memory, 9, 1, pp. 376-392.

Fritsch, Matthias (2001): “History, Violence, Responsibility”. En: Rethinking History, 5, 2, pp. 285-304.

Fukuyama, Francis (1992): The End of History and the Last Man. New York/Toronto: Free Press/Maxwell Macmillan Canada.

Gateward, Frances/Pomerance, Murray (2002): "Introduction”. En: Gateward, Frances/Pomerance, Murray (eds.): Sugar, Spice, and Everything Nice. Cinemas of Girlhood. Detroit: Wayne University Press, pp. 13-24.

Harvey, David (2000): Spaces of Hope. Berkeley: University of California Press.

Hentges, Sarah (2006): Pictures of Girlhood. Modern Female Adolescence on Film. London: MacFarland \& Company Publishers.

Horkheimer, Marx/Adorno, Theodor (2002): Dialectic of Enlightenment. New York: Continuum.

Jameson, Frederic (1999): Postmodernism, or, the Cultural Logic of Late Capitalism. Durham: Duke University Press.

Jardine, Murray (1998): “Are Communitarians 'Premodern' or 'Postmodern'? The Place of Communitarian Thought in Contemporary Political Theory”. En: Lawler, Peter Augustine/McConkey, Dale (eds.): Community and Political Thought Today. London: Praeger, pp. 27-38.

Nash, Ilana (2006): American Sweethearts. Teenage Girls in Twentieth-Century Popular Culture. Bloomington: Indiana University Press.

Nussbaum, Martha (1999): "The Professor of Parody". En: The New Republic, 22, pp. $40-45$.

Ong, Aihwa (2006): "Experiments with Freedom: Milieus of the Human". En: American Literary History, 18, 2, pp. 229-244. 
Pope, Randolph (2008): "Madrid in the Novel". En: Altisent, Marta (ed.): A Companion to the Twentieth-Century Spanish Novel. London: Tamesis, pp. 129-136.

Rodríguez Chico, Julio (2003): "Una generación perdida y desencantada". En: <www. labutacanet/51 sansebastian/laflaquezadelbolchevique4.htm $>$ (10.09. 2008).

Rodríguez Marchante, Otti (2003): "Mejor La flaqueza del bolchevique que la histeria de Mañas". En: <www.abc.es/hemeroteca/historico-23-09-2003/abc/ Espectaculos/mejor-la-flaqueza-del-bolchevique-que-la-histeria-dema\%C3\%B1as-o-la-pesadez-de-rivette_209239.html > (17.09.2008).

Silva, Lorenzo (1997): La flaqueza del bolchevique. Barcelona: Destino.

Smith, Steve (2003): The Russian Revolution. Oxford: Oxford University Press.

Stewart, Kathleen (1988): "Nostalgia - A Polemic". En: Cultural Anthropology, 3, 3, pp. 227-241.

Svašek, Maruška (2006): "Postsocialism and the Politics of Emotions”. En: Svašek, Maruška (ed.): Postsocialism. New York: Bregan Books, pp. 1-33.

Waters, Malcolm (2001): Globalization. London: Routledge.

Weber, Max (1978): Economy and Society: An Outline of Interpretative Sociology. Vol. I. Berkeley: University of California Press.

Žižek, Slavoj (1999): The Ticklish Subject. The Absence Centre of Political Ontology. London: Verso. 